5. Лотман, Ю. М. Семиосфера. Санкт-Петербург : Искусство, 2010. - 704 с. - Текст : непосредственный.

6. Емельянов, В. В. Исторический прогресс и культурная память (о парадоксах идеи прогресса). - Текст : непосредственный // Вопросы философии. - 2011. - № 8. - С. 46-57.

Olga V. Pervushina, Ph. D. in Cultural Science, Associate Professor Altai State Institute of Culture (Barnaul, Russia) agaki-pervushina@yandex.ru

\title{
CULTURAL MEMORY: PROBLEMATIC FIELDS FOR RESEARCH
}

\begin{abstract}
The paper presents comparative analysis of views of major historians of culture, sociologists, semiologists, cultural specialists of Russia and Europe of the $19^{\text {th }}$ and $20^{\text {th }}$ centuries on cultural memory phenomenon which is considered as sustainable feature of social life, a specific symbolic construct with its own structure, laws of dynamics, mechanisms of selection. The author describes dominant approaches in humanitarian and social sciences to understanding a concept "cultural memory", clears up an issue about its correlation with definitions "individual memory" and "collective memory". Also, the paper lists the key areas for scientific research in cultural memory phenomenon that require scholars' attention.

Key words: cultural memory, collective memory, individual memory, a cultural tradition, succession, traditional culture, a symbolic construct, a text.
\end{abstract}

УДК 069:001.89:719 (571.14-25)

DOI: 10.32340/2414-9101-2019-2-38-43

Н. Н. Покровский, кандидат исторических наук Институт истории Сибирского отделения Российской академии наук

(Новосибирск, Россия) pokrov@li.ru

О. Н. Шелегина, доктор исторических наук Институт истории Сибирского отделения Российской академии наук (Новосибирск, Россия) oshelegina@yandex.ru

Г. М. Запорожченко, доктор исторических наук Институт истории Сибирского отделения Российской академии наук

(Новосибирск, Россия) galinakoop@yandex.ru

\section{ДОСТОПРИМЕЧАТЕЛЬНОЕ МЕСТО «НОВОСИБИРСКИЙ АКАДЕМГОРОДОК» - СОЦИОКУЛЬТУРНЫЙ РЕСУРС МЕГАПРОЕКТА «АКАДЕМГОРОДОК 2.0»}

Аннотация. Охарактеризован исторический контекст появления в 1957 г. первого в Сибири наукограда (технополиса) - Новосибирского Академгородка - c инновационной научноисследовательской, научно-производственной, образовательной, культурно-досуговой и бытовой инфраструктурой. Представлены результаты авторских исследований в области конвертации исторического опыта в ресурс конструирования устойчивой идентичности личности и социальных групп; изложена аргументация в пользу применения к Новосибирскому Академгородку концепта «научный monoc», рассматриваемого авторами в качестве одной из разновидностей регионально-локальной идентичности. Представлены авторские соображения о потенциале внедрения в грантосоискательские, социально-культурные, информационно-коммуникационные и образовательные практики методик выявления и презентации социокультурных комплексов достопримечательных мест, изложенные в научно-популярном издании Института истории Сибирского отделения Российской академии наук (Новосибирск, Россия) «Достопримечательное место “Новосибирский Академгородок”: научное и историко-культурное наследие» (Новосибирск, 2019). 
Ключевые слова: Новосибирский Академгородок, российский наукоград, технополис, научный топос, Академгородок 2.0, достопримечательное место, социокультурное пространство, научное наследие, историко-культурное наследие, Институт истории Сибирского отделения Российской академии наук.

В соответствии с перспективным национальным проектом пространственного развития России новыми точками роста науки должны стать научно-образовательные и исследовательские центры мирового уровня в Сибири и на Дальнем Востоке.

«Новосибирск - научная столица Сибири», «Академгородок 2.0», «Сибирский технополис»актуальные и весьма значимые для реализации Стратегии научно-технологического развития России проекты и концепции.

8 февраля 2018 г., во время визита Президента Российской Федерации В. В. Путина в Новосибирский Академгородок председатель Сибирского отделения Российской академии наук (далее СО РАН), академик В. Н. Пармон предложил использовать Новосибирский научный центр (далее - ННЦ) в качестве пилотной модели для развития современных научных центров в России. Президент РФ поручил к сентябрю 2018 г. разработать такого рода модель и представить её на рассмотрение Совета по науке и образованию при Президенте РФ. Стартовый вариант инновационной модели был представлен на крупном международном форуме «Технопром - 2018» (август, 2018, г. Новосибирск) в форме мега-проекта «Академгородок 2.0». Цель проекта декларировалась как формирование современного научно-технологического комплекса, способного обеспечить: достижение научного и технологического лидерства региона и России; рост доходов на душу населения, сопоставимый с передовыми странами; оптимальные условия для реализации и развития человеческого капитала [1].

На этапе дальнейшей разработки проекта «Академгородок 2.0» под названием «Концепция развития Новосибирского научного центра (Новосибирского Академгородка) как территории с высокой концентрацией исследований и разработок» актуализировались проблемы, связанные с его социокультурной составляющей. Научной общественностью обоснована необходимость проведения гуманитарной экспертизы проекта [2], начал работать проектный семинар «Академгородок 2.0» как самостоятельное инициативное действие, предполагающее самоорганизацию местного экспертного и гражданского сообщества Академгородка для выстраивания продуктивных горизонтальных связей между участниками проекта. Существенное значение в этой ситуации приобретает формирование активной и созидательной гражданской позиции населения, молодёжи по освоению научного и историко-культурного наследия достопримечательного места регионального значения «Новосибирский Академгородок», интеграция науки, образования, культуры.

Важным социокультурным ресурсом мегапроекта «Академгородок 2.0» может стать совокупность теоретических и научно-практических разработок, связанных с научной идентичностью, историко-культурным наследием «Новосибирского Академгородка», выполненных в секторе «Музей СО РАН» и получивших дальнейшее развитие в рамках проекта «Политические и социокультурные практики населения Сибири в XX - начале XXI вв.» Института истории СО РАН. Новое гуманитарное знание в данном контексте основывается на репрезентативном историографическом ресурсе, включающем фундаментальные труды по истории сибирской науки, публикации российских и зарубежных ученых с новыми подходами к изучению проблем наследия.

В связи с тем, что «Академгородок 2.0» позиционируется как мировой научно-технологический лидер - инновационный научный город, был проведён историко-социологический анализ наукоградов в Сибири [3]. Опыт их создания и функционирования, адаптации к экономической и социокультурной динамике весьма значим для комплексной разработки новых проектов. Следует отметить, что до настоящего времени главным образом изучались научно-организационные и научнотехнологические проблемы наукоградов. Вместе с тем современная ситуация, во избежание технологического детерминизма этих территорий, требует акцентуации внимания на социокультурном пространстве наукоградов, обеспечивающем развитие человеческого капитала, определяющего долгосрочные перспективы и конкурентоспособность страны. 
До принятия Федерального закона № 70-Ф3 «О статусе наукограда Российской Федераџии» (1991 г.) в Сибири уже имелись территориальные локации, обладающие признаками наукоградов в их современном понимании. Несомненно, первым сибирским наукоградом можно считать научный городок Сибирского отделения Академии наук СССР (с 1957 г.), впоследствии широко известный как Новосибирский Академгородок с новационной моделью («Треугольник Лаврентьева»), научноисследовательской, образовательной, научно-производственной инфраструктурой, креативной культурой жизнедеятельности учёных.

Успешной реализации этой модели, обусловленной наряду с мощным государственным финансированием, кадровой поддержкой центральных научно-исследовательских институтов, организацией вуза нового типа - Новосибирского государственного университета, развитием системы технологических организаций, по нашему мнению, способствовало, в том числе, определение перспектив формирования социокультурного пространства с учётом имеющегося природного наследия, социально-экономического и культурного потенциала города Новосибирска.

Обратим внимание на объективные факторы выбора места для научного центра, их оценку академиком М. А. Лаврентьевым - одним из инициаторов, организаторов и первым председателем Сибирского отделения Академии наук СССР. «В Новосибирске площадка под будущий Академгородок была выбрана единодушно. Здесь нас устраивало все: близость крупного промышленного и культурного центра и все же достаточное от него удаление, чтобы городок науки не растворился в большом городе, сохранил внутреннее единство; наличие самого крупного в Сибири филиала Академии наук и его дружественное отношение к проекту нового научного центра, удобство транспорта (узел на Транссибирской магистрали, аэропорт с прямыми рейсами в Москву, наконец, наличие шоссе почти до места строительства). Не последнюю роль сыграли природные условия: мягкий рельеф, прекрасные берёзовые рощи и полоса соснового бора вдоль Оби ...» [4, с. 160]. В действительности для размещения научного городка в 25 км от Новосибирска выделялось 1100 гектаров площади, на 750 га рос смешанный лес, на западной границе участка находилось водохранилище Новосибирской гидроэлектростанции. В Новосибирске имелись экономические и социокультурные предпосылки для развития фундаментальной науки, позволившие ему обеспечить «академический прорыв» [5, с. 447].

Академгородок стал одним из первых отечественных урбанизированных поселений, изначально возведённых в соответствии с утверждённым планом строительства [5, с. 450-451]. Возведение научных институтов шло одновременно с жилым фондом и объектами культурного и социально-бытового характера. М. А. Лаврентьев справедливо считал: «в научном поселении должно быть все: ... Дом учёных, гостиницы, кино, школы, ясли, должен быть социалистический город нового, современного типа» [4, с. 161].

Новации были связаны с проектированием и строительством научного поселения с перспективной системой жизнеобеспечения, называемой сейчас стиль «эко».

Одной из главных детерминант социокультурного пространства (во всех его проявлениях экономическом, политическом, туристическом) Новосибирского Академгородка, отличавшего его от поселений научного профиля в России (будущих наукоградов) стала открытость. Концентрированная в нем научная сфера Сибири стала привлекательной территорией для зарубежных научных и деловых кругов, что способствовало развитию международного сотрудничества, расширению образовательных и культурных контактов. Новосибирский Академгородок начали называть «сибирским чудом $\mathrm{XX}$ века», считать определённым «культурным высказыванием», сложившимся во второй половине XX - начале XXI вв. Вполне закономерно, что в 2014 г. Новосибирский Академгородок с богатым научным и историко-культурным наследием, уникальной природной средой получил статусдостопримечательного места регионального значения с мировой известностью [6, с. 13].

В результате реализации междисциплинарного проекта «Современные тенденции в актуализации исторического опыта формирования идентичностей в Сибирском регионе», выполненного в Институте истории СО РАН, впервые было предложено рассматривать Новосибирский Академгородок как научный топос - феномен регионально-локальной идентичности [7].

Концепт «научный топос» можно считать новацией, расширяющей подходы к проектированию социокультурного пространства перспективных научных поселений, прежде всего «Академгородка 
2.0». Данный концепт описывает отношения «пространство-человек-наука-культуранаследие», применим для анализа локально-организованных смыслообразующих пространств (поселений), имеющих определенную локацию, характеризующуюся научной идентичностью. Признаками научного топоса может являться наличие определенных социокультурных комплексов, которые маркируют и транслируют научное и историко-культурное наследие.

В процессе изучения достопримечательного места «Новосибирский Академгородок» с позиций современных подходов к историко-культурному и природному наследию как стратегическому фактору развития регионов России, положений мнемософии (науки о публичной памяти) были выделены и описаны актуальные и перспективные базовые социокультурные комплексы: мемориальномонументальный (памятники и мемориальные доски, посвящённые выдающимся учёным и гражданам); музейный (музеи и объекты музейного значения); топонимический (отражение научного профиля в названиях улиц и объектов); интеллектуально-досуговый (формы, деятельность объектов культуры, общественного быта); экологический (ландшафтно-природные зоны рекреации жизнедеятельности с информационной нагрузкой).

С проявлением гражданской инициативы, самодеятельного творчества, развитием социокультурного пространства научного топоса связано формирование новационных комплексов: аттрактивного (арт-объекты с научной символикой) и ивентового (знаковые события и мероприятия) [6, c. 148-159], определяющих креативную среду жизнедеятельности учёных. В Академгородке инициирован и проведен первый в России фестиваль стрит-арта «Графит науки» по оформлению научных и социальных объектов граффити, популяризирующих науку. На городском уровне в 2016-2018 гг. проходил фестиваль «Академина» для женщин, работающих в сфере науки, образования, экономики, первоначально возникший в Новосибирском академическом городке. До всероссийских масштабов вырос общественный проект «Тотальный диктант по русскому языку»-ежегодная образовательная акция для всех желающих независимо от возраста, вероисповедания, политических взглядов, проводимая под руководством известных писателей.

В определённой степени мобилизационный характер, направленный на опережающие темпы развития отечественной науки, носят ежегодные всемирные конгрессы выпускников Новосибирского государственного университета, круглый стол «Новосибирский Академгородок между прошлым и будущим. В чем сила, брат?» в коммуникационно-дискуссионном пространстве «Точка кипения» $\mathrm{AO}$ «Технопарк» в рамках российского культурно-исторического форума «Место силы и свободы. Академгородок» (март 2018 г.). Все это является резервом для реализации концепции современного развития первого сибирского наукограда как центра «Наука - Образование - Инновации», исторически сложившейся и успешно функционирующей модели научного топоса, имеющей высокий адаптивный потенциал к новым технологическим и социокультурным условиям XXI столетия.

С целью внедрения в проектную, социальную, информационно-коммуникационную, образовательную практику представленной выше теории и методики выделения и презентации социокультурных комплексов достопримечательных мест авторами данной статьи было опубликовано научнопопулярное издание «Достопримечательное место “Новосибирский Академгородок”: научное и историко-культурное наследие» [6].

Эмпирическую базу работы составили данные, полученные при пространственном изучении и фиксации объектов наследия и культуры жизнеобеспечения Новосибирского научного центра в ходе многолетней деятельности авторов в музейных подразделениях Института истории СО РАН, а также посредством метода «включённого наблюдения» авторов - жителей Академгородка. Книга носит экспериментальный характер и построена по модульному принципу, предполагающему диффузность, комплементарность блоков (глав). На примере Новосибирского Академгородка выделены детерминанты научного топоса - достопримечательного места. Среди них: диверсификация социокультурных комплексов; дисперсный характер трансляции регионально-локальной идентичности, синергия государственных структур и общественных институций в освоении историко-культурного наследия, развитый научно-образовательный комплекс. Как пространственная системная научно-организационная доминанта достопримечательного места «Новосибирский Академгородок» рассматривается проспект академика Лаврентьева - «самая умная улица мира» (по версии книги рекордов Гиннеса). Такое определение проспект получил в связи с максимальной 
концентрацией на протяжении 2,4 км более 20 исследовательских институтов, конструкторскотехнологических бюро, научных кадров высшей квалификации. Символично, что начинается проспект билбордом со словами М. В. Ломоносова «Российское могущество прирастать будет Сибирью ...». Приоритетная роль личности академика М. А. Лаврентьева в создании Сибирского отделения Академии наук СССР, ННЦ, социокультурного пространства Академгородка соотносится с распространённым в мировой практике концептом «гений места» («дух места», «гений локуса»). При характеристике институтов важная роль отведена первому из созданных в начале Проспекта Науки (с 1981 г. - проспект Лаврентьева) - Институту гидродинамики им. М. А. Лаврентьева. Интерес представляет история и современный научно-исследовательский потенциал Института ядерной физики им. Г. И. Будкера, Института катализа им. Г. К. Борескова, занимающих статусные позиции в проекте «Академгородок 2.0». Образно, с использованием значительного числа исторических и современных фотографий, в названном издании информация о проспекте М. А. Лаврентьева излагается в контексте метафоры «улица - стержневое русло - артерия большой науки», в которую вливаются улицы и лесные тропинки, названные в честь известных учёных, что составляет отличительную топонимическую особенность городка.

К институтам публичной памяти о выдающихся ученых, работавших в Новосибирском Академгородке, относятся: памятники академикам М. А. Лаврентьеву, В. А. Коптюгу, Д. К. Беляеву, бюсты академиков А. А. Трофимука, В. С. Соболева (Институт геологии и минералогии СО РАН), А. П. Окладникова (Институт археологии и этнографии СО РАН). 10 улиц и проспектов названы именами ученых, на зданиях институтов, жилых домов, физико-математической школы установлено 56 мемориальных досок. 13 институтов ННЦ носят имена своих первых директоров, что можно считать своеобразным проявлением эффективной кадровой стратегии организации институтов СО АН СССР «под директора» - научного лидера, формировавшего институт в соответствии со своей авторской концепцией. Сегодня имена основателей институтов, известных сибирских ученых и научных направлений прочно вошли в историю российской и мировой науки. Учреждено 22 именных стипендии для студентов и молодых учёных, более 20 книг вышли в серии «Сибирская наука в лицах», создано 7 мемориальных комнат, персональные фонды ряда учёных хранятся в секторе «Музей СО РАН». Все это активно используется в целях коммеморации, воспитания уважения и гордости за научных предшественников, свидетельствует о целесообразности развития институтов публичной памяти в достопримечательном месте «Новосибирский Академгородок».

Креативная среда жизнедеятельности в достопримечательном месте, базирующаяся на важных компонентах «академовской» идентичности: свободе дискуссий в научной и общественной жизни, демократизме в общении маститых академиков и молодых ученых, гордости научной интеллигенции за уникальность городка - успешно развивается на основе функционирования вышеописанных традиционных социокультурных комплексов: топонимического, монументального, экологического, интеллектуально-досугового, новационных - аттрактивного и ивентового (знаковые события и мероприятия).

Сочетание в представляемой книге теоретических и информационных аспектов, а также возможность их автономного использования в социокультурной практике позволяет оперативно дополнять издание новыми разработками и сведениями, адаптировать к публикации в интернете, способствует активному внедрению в образовательное пространство научных достижений, развитию креативной экономики, международного сотрудничества. Это издание с глубоким уважением и благодарностью посвящённое всем жившим и творившим в Академгородке, адресованное нынешним жителям и гостям достопримечательного места «Новосибирский Академгородок», коллегам и создателям нового научного топоса - «Академгородок 2.0», вызвало широкий общественный резонанс и интерес.

Площадкой для реализации проекта «Академгородок 2.0» становится не только Новосибирский научный центр, а практически вся Новосибирская область. В числе приоритетных задач проекта: развитие научной и научно-производственной кооперации; развитие передовой инфраструктуры для проведения исследований и разработок; развитие кадрового потенциала Сибири в сфере исследований и разработок; развитие комфортной социальной среды для жизни и творческого потенциала учёных. Мегапроект «Академгородок 2.0» будет объединять свыше 30 проектов, среди которых выделяется первоочередное создание трёх ключевых центров: Сибирского кольцевого источника фотонов 
«СКИФ»; Центра компетенций «Генетические технологии»; Центра высокопроизводительных вычислений, обработки и хранения данных «СНЦ ВВОД». Вместе с тем предложено два перспективных проекта с выраженной социокультурной и образовательной ориентацией: «Многофункциональный центр коммуникаций науки, бизнеса, образования» и «“Открывариум”- мультидисциплинарный музейный комплекс СО РАН». Для их разработки и реализации будут актуальны и востребованы алгоритмы интеграции науки, образования, культуры в сфере наследия в информационном обществе, апробируемые в Центре популяризации науки Института истории СО РАН, потенциал научного наследия, сосредоточенный в музейных структурах институтов СО РАН, Музее науки и техники CO PAH.

\title{
Список литературы
}

1. Кичанов, М. С претензией на лидерство. - Текст : непосредственный // Эксперт Сибирь. - 2018. № 37/38. - C. 8-10.

2. Смирнов, С. А. Мы подкладываем себе прошлое. Гуманитарная экспертиза проекта «Академгородок 2.0». - Текст : электронный // Тайга.инфо, региональное [Сибирский федеральный округ] информационное агентство : [сайт]. - URL: https://tayga.info/144882 (дата обращения: 10.02.2019).

3. Орлов, С. Б. Наукограды в Сибири: историко-социологический анализ / С. Б. Орлов, О. Н. Шелегина. Текст : непосредственный // Инноватика и экспертиза. - 2019. - Вып. 1. - С. 156-165.

4. Российская академия наук. Сибирское отделение. Исторический очерк / Е. Г. Водичев, С. А. Красильников, В. А. Ламин [и др.]. - Новосибирск: Наука, 2007. - 500 с. - Текст : непосредственный.

5. История города. Новониколаевск - Новосибирск. Исторические очерки : [монография] / С. А. Красильников, Г. А. Бочанова, С.С. Букин. - Новосибирск : ИД Историческое наследие Сибири, 2013. - 800 с.

6. Покровский, Н. Н. Достопримечательное место «Новосибирский Академгородок»: научное и историкокультурное наследие / Н. Н. Покровский, Г. М. Запорожченко, О. Н. Шелегина. - Новосибирск : ИПЦ НГУ, 2018. - 162 с. - Текст : непосредственный.

7. Шелегина, О. Н. Идентичность локальных научных сообществ: опыт формирования и трансляции (по материалам Новосибирского научного центра $\mathrm{CO}$ РАН)/ О. Н. Шелегина, Н. А. Куперштох, Г. М. Запорожченко, Н. Н. Покровский. - Текст : непосредственный // Гуманитарные науки Сибири. - 2016. T. 25, № 3. - C. 117-122.

Nikolai N. Pokrovskii, Ph. D. in History Institute of History of Siberian Branch of the Russian Academy of Sciences (Novosibirsk, Russia) pokrov@li.ru

Olga $N$. Shelegina, Dr. of Historical Sciences Institute of History of Siberian Branch of the Russian Academy of Sciences (Novosibirsk, Russia) oshelegina@yandex.ru

Galina. M. Zaporozhchenko, Dr. of Historical Sciences Institute of History of Siberian Branch of the Russian Academy of Sciences (Novosibirsk, Russia) galinakoop@yandex.ru

\section{PLACE OF INTEREST "NOVOSIBIRSK AKADEMGORODOK", SOCIAL AND CULTURAL RESOURCE OF MEGAPROJECT “AKADEMGORODOK 2.0”}

\begin{abstract}
The article discloses historical background for origin of the first academic town (technopolis) in Siberia (in Russian: Academgorodok), 1957, which had its own support structure for scholars' research work, industrial, educative, leisure, and household activities. The paper outlines the results of the authors' research studies in sphere of converting historical experience into a resource for building a sustainable identity for a personality and social groups; the authors argue a status "scientific locus" for Novosibirsk Academgorodok, this status is considered by the researchers as a sort of a personality's regional and local identity. Also, the authors share their own ideas in adapting techniques for detecting and presenting social and cultural complexes of sightseeing to project, social, cultural, information, educative activities outlined in a book called "Place of Interest 'Novosibirsk Akademgorodok': Scientific, Historical, and Cultural Heritage" is-sued by The Institute of History of Siberian Branch of the Russian Academy of Sciences (Novosibirsk, Russia) in 2019.

Key words: Novosibirsk Akademgorodok (Academic Town), Russian technopolis, technopolis, scientific topos/locus, Akademgorodok 2.0, place of interest, social and cultural space, scientific heritage, historical heritage, cultural heritage, Institute of History of Siberian Branch of the Russian Academy of Sciences.
\end{abstract}

